\title{
Determinants of the income velocity of money in Portugal: 1891-1998
}

\author{
Ana Bela Nunes ${ }^{1} \&$ Miguel St. Aubyn ${ }^{2}$ (DD \& \\ Nuno Valério ${ }^{1}$ \& Rita Martins de Sousa ${ }^{1}$
}

Received: 23 July 2015 / Accepted: 18 December 2017 / Published online: 8 January 2018

\# ISEG 2018

\begin{abstract}
This paper performs a long-run time series analysis of the behaviour of the income velocity of money in Portugal between 1891 and 1998 by assessing the importance of both macroeconomic and institutional factors and looking for particularities in the Portuguese case. We estimate two cointegration vectors for the income velocity of money, macroeconomic variables and institutional variables. It is apparent that one of these vectors reflects the relationship between income velocity and macroeconomic variables, while the other reflects the relationship between income velocity and institutional variables. Moreover, a regression analysis reveals that the usual U-shaped pattern is displayed with a relatively late inflection point located around 1970, which is consistent with the Spanish case. It is further noted that this is a feature of countries with a late economic and institutional development process.
\end{abstract}

Keywords Velocity of money $\cdot$ Portugal $\cdot$ Cointegration $\cdot$ Institutional determinants

JEL Classification $\mathrm{E} 41 \cdot \mathrm{E} 50 \cdot \mathrm{N} 10$

* Miguel St. Aubyn

mstaubyn@iseg.ulisboa.pt

1 ISEG, (Lisbon School of Economics and Management), GHES-CSG (Research Unit on Economic and Social History), Universidade de Lisboa, Lisbon, Portugal

2 ISEG, (Lisbon School of Economics and Management), UECE/REM (Research Unit on Complexity and Economics), Universidade de Lisboa, Rua Miguel Lupi 20, P1249-078 Lisbon, Portugal 